\title{
Urdimento
}

Revista de Estudos em Artes Cênicas

E-ISSN: 2358.6958

\section{Teatro e Prisão: experiências que se transformam em linguagem}

Flávia Janiaski Vale Márcia Gomes

Alan Aguiar

\section{Para citar este artigo:}

JANIASKI VALE, Flávia; GOMES, Márcia; AGUIAR, Alan. Teatro e Prisão: experiências que se transformam em linguagem. Urdimento, Florianópolis, v. 3, n. 39, nov./dez. 2020.

DOI: http:/dx.doi.org/10.5965/14145731033920200122

Este artigo passou pelo Plagiarism Detection Software | iThenticate 


\title{
Teatro e Prisão: experiências que se transformam em linguagem
}

\author{
Flávia Janiaski Vale \\ Márcia Gomes ${ }^{2}$ \\ Alan Aguiar ${ }^{3}$
}

\begin{abstract}
Resumo
O presente artigo, construído a seis mãos, nasceu da necessidade de transformar uma experiência em linguagem. Desta forma, ele versa sobre a oficina de teatro realizada entre agosto e dezembro de 2019 na Unidade Educacional de Internação para menores infratores - UNEI Laranja Doce na cidade de Dourados/ (MS), com dez adolescentes entre 13 e 17 anos. A escrita partiu do anseio de pensar e contar a experiência cênica-pedagógica vivenciada durante a oficina, apresentando aspectos relacionados a sua criação, estrutura e desenvolvido.
\end{abstract}

Palavras-Chave: Teatro. Prisão. Pedagogia das artes cênicas. Teatro do Oprimido.

\section{Theater and Prison: experiences that become language}

\begin{abstract}
This essay, written by three collaborators, was born from the need to transform an experience into language. This article describes a theater workshop that happened between August and December 2019 in a juvenile offenders system called UNEI Laranja Doce in the city of Dourados (MS), with ten teenagers between 13 and 17 years old. This article emerged from the desire to think and tell about the pedagogical and practical experience of the live workshop. The article describes the workshop's creation, structure, and development.
\end{abstract}

Keywords: Theater. Prison. Performing arts pedagogy. Theater of the oppressed.

${ }^{1}$ Doutora em Artes Cênicas - Universidade Federal da Bahia (UFBA), com bolsa de doutorado sanduiche pela CAPES na University of Massachusetts/Boston no programa de Early Childhood Education. Profa. Dra. Adjunta da Universidade Federal da Grande Dourados (UFGD) em Mato Grosso do Sul (MS). flajaniaski@hotmail.com

${ }^{2}$ Licenciada em Artes Cênicas pela Universidade Federal da Grande Dourados (UFGD). Atriz e pesquisadora, foi bolsista do PIBID/Teatro durante três anos, onde teve a oportunidade de trabalhar na educação básica e apresentar contação de histórias nas escolas parceiras. marcinhaa gomes@gmail.com

${ }^{3}$ Licenciado em Artes Cênicas pela Universidade Federal da Grande Dourados - UFGD. Ator e pesquisados, membro da Cia Última Hora (Companhia teatral de Dourados - MS). Foi bolsista do PIBID/teatro por três anos. alan_agsilva@hotmail.com 


\section{Teatro y prisión: experiencias que se convierten en lenguaje}

\section{Resumen}

Este artículo, construido con seis manos, nació de la necesidad de transformar una experiencia en lenguaje. De esta manera, habla sobre el taller de teatro realizado entre agosto y diciembre de 2019 en la Unidad de hospitalización educativa para delincuentes juveniles - UNEI Laranja Doce en la ciudad de Dourados (MS), con diez adolescentes entre 13 y 17 años. La escritura comenzó del deseo de pensar y contar la experiencia escénica-pedagógica vivida durante el taller, presentando aspectos relacionados con su creación, estructura y desarrollo.

Palabras clave: Teatro. Prisión. Pedagogía de artes escénicas. Teatro de los oprimidos. 
Ser cidadão não é viver em sociedade é transformá-la. (Augusto Boal)

O historiador inglês Michel Balfour discute no livro Theatre and War, 19331945: Performance in Extremis e na introdução do livro Theatre in Prison: Theory and Pratice a ideia de que o Teatro e a Arte são formas de autoafirmação pessoal, assim como maneiras que as pessoas encontram para se sentirem humanas. Balfour apresenta evidências de que o teatro, assim como outras formas do fazer artístico, estiveram presentes na Segunda Guerra Mundial, em campos de concentração, em prisões comunistas (Gulagss), nos guetos, entre outros lugares de extremo sofrimento, aprisionamento e privação de direitos básicos. Este fazer artístico foi capaz de devolver - ainda que por um breve momento - a identidade individual e coletiva das pessoas que se encontravam naquelas condições: a música, o desenho, a performance, a pintura, contação de história, poesias, etc., produzida em meio ao caos e a violência, foi capaz de transformar medos em liberdade; capaz de dar esperança e vontade de viver às pessoas imersas em situações extremas. E ainda que não tenha salvo suas vidas a longo prazo, salvaram sua humanidade em cada dia a mais que viveram e fizeram arte. Segundo Balfour:

Estes traços da história do teatro nas prisões são importantes, porque, assim como na prática contemporânea, eles levantam questões sobre a natureza e a razão dos processos criativos dos encarcerados. Por quê um índio arriscaria sua vida para roubar papel para desenhar? Porque uma pessoa faminta em um campo de concentração guardaria comida para usá-la como pigmento colorido em uma pintura? Estas questões apontam para uma necessidade de criatividade que vai além da percepção básica de arte como entretenimento, lazer ou mesmo educação. Nesses contextos extremos, onde era muito mais fácil desistir do que ter uma centelha de esperança e humanidade, as pessoas arriscaram-se para criar e encontrar uma fuga temporária, um momento de resistência contra sistemas de poder formalizados e difundidos. (Balfour, 2004, p. 2). ${ }^{4}$ 
Mesmo em espaços de privação de liberdade, os indivíduos sentem a necessidade da Arte por ela ser capaz de lhes dar algum sentido de existência, esperança e resistência. Desta maneira, o teatro tem o potencial de ser uma ferramenta capaz de representar para as pessoas a experiência de se sentirem humanas, de autoconhecimento e de liberdade. O teatro possui qualidades artísticas, estéticas, de lazer, de entretenimento, etc., e também pode ser usado como instrumento educacional, de socialização e de reabilitação de indivíduos.

Por outro lado, trabalhar teatro dentro de uma prisão ou de uma unidade educacional de internação para menores é um tanto contraditório, pois o teatro, de forma geral, propõe práticas libertárias, ou seja, parte do princípio de necessidade de liberdade para a construção artística. Desta forma, como realizar uma prática alicerçada na liberdade de expressão, corporal e do pensamento, dentro de um espaço que institui regras rígidas, punições, repressão, coerção, entre outras práticas de aprisionamento físico, intelectual e psicológico?

Tivemos que pensar muito nesta questão para a confecção de um projeto de oficina de teatro a realizar-se Unidade Educacional de Internação para menores infratores - UNEI Laranja Doce na cidade de Dourados/MS. No curso de Artes Cênicas da Universidade Federal da Grande Dourados/UFGD os alunos da licenciatura precisam realizar três semestres de estágio curricular supervisionado, onde o discente tem autonomia para escolher o local e a temática que gostaria de desenvolver seu estágio e a regência pode ser realizada no ensino formal ou não formal, assim como em comunidades e espaços alternativos. No ano de 2019 uma dupla de estagiários apresentou o desejo de desenvolver seu estágio com adolescentes internos da UNEI.

Este desejo foi abraçado pela orientadora de estágio e começamos então as preparações para realizar uma prática de estágio dentro de um espaço de cárcere. O primeiro passo foi tentar entender este o funcionamento burocrático e prático

risk being killed in order to steal paper to draw on? Why would a starving person in a concentration camp hold back food to use it as color pigment on an elicit painting? These questions point to a need for creativity that goes beyond the basic perception of art as entertainment, leisure or even education. In these extreme contexts, where it was far easier to give up than it was to have a spark of hope and humanity, people took the risk to create and find a temporary escape, a moment of resistance, against formalized and pervasive systems of power. (Tradução nossa). 
deste universo que era novo para todos os envolvidos, pois seria a primeira vez que o fazer teatral adentraria o espaço da UNEI, assim como também seria a primeira vez que os discentes trabalhariam em um ambiente do gênero e que a docente orientaria uma prática com estas particularidades, tornando-se assim um desafio para todos os envolvidos.

Desta forma, os alunos Marcia Gomes e Alan Aguiar, sob orientação da Prof. Dra. Flávia Janiaski realizaram entre os meses de agosto a dezembro de 2019 uma oficina de teatro dentro da UNEI Laranja Doce para dez adolescentes entre 13 e 17 anos. Os encontros aconteceram duas vezes por semana com duração de 3 horas cada. O projeto e a preparação de cada atividade, foi realizado em conjunto entre discentes e docente orientadora, com o objetivo de tecer ações que pudessem construir um campo de diálogo e compartilhamentos entre UNEl e o curso de Artes Cênicas.

A UNEl é um espaço socioeducativo com o objetivo de ressocializar menores infratores, ou seja, de torná-los parte da sociedade novamente. Para isso é preciso que sejam realizadas ações efetivas que visem a não reincidência à criminalidade, assim como, medidas para que após os menores cumprirem seu período de internação sejam reintegrados à sociedade estudando e/ou trabalhando. O período de permanência de cada menor na instituição varia de acordo com sua pena/crime (3 anos no máximo).

A unidade de Dourados foi inaugurada no ano de 2001 com capacidade de atender 24 internos, após reforma realizada no prédio a capacidade de atendimento aumentou para 40. Durante o período que os adolescentes e jovens se encontram na UNEI eles continuam a desenvolver seus estudos, pois lá existem salas de aulas e professores disponibilizados pela secretaria estadual de educação. Não existe um regimento padrão (disponibilizado pelo Estado) para as atividades e funcionamento de cada unidade, portanto, cabe a elas organizarem seus organogramas de funcionamento, confeccionar seus protocolos de visitas, assim como a saídas dos internos para atividades externas e aulas.

Além das atividades escolares são oferecidos cursos de pequena e média 
duração, através de parcerias entre a UNEI e outras instituições governamentais e não governamentais. Alguns exemplos são: o curso de menor aprendiz para o ambiente de trabalho ${ }^{5}$ ofertado pelo Centro de Integração Empresa Escola (CIEE); o curso de manutenção de computadores em parceria com o Instituto Federal do Mato Grosso do Sul (IFMS); entre outros cursos ofertados pela UFGD; pelo Serviço Nacional de Aprendizagem Rural (SENAR); e pelo Instituto Agrícola do Menor (IAME).

O diretor da UNEl (José Marcondes Nantes de Brito) relata que o primeiro desafio que se apresenta para a instituição é a lotação acima do previsto e permitido por lei, tendo em vista que no momento da realização da oficina a UNEI contava com 60 internos, sendo que sua capacidade, como dito acima, era para 40 detentos. Esta superlotação aliada à insuficiência de agentes, inviabiliza o propósito da instituição, que é de ser um local de aprendizado capaz de garantir aos menores infratores o direito à ressocialização e à prevenção de reincidência, direito este previsto no Estatuto da Criança e do Adolescente ${ }^{6}$ (ECA).

De acordo com o ECA o adolescente que comete qualquer "infração penal" deve ser penalizado através das medidas socioeducativas, que têm como principal objetivo a recuperação social do menor infrator. Para isso, o Estado deve contar com uma série de políticas públicas visando à readaptação, onde tanto o adolescente, quanto a comunidade na qual ele está inserido, tem responsabilidade por seus atos. As medidas socioeducativas variam de acordo com a infração cometida e são: advertência; obrigação de reparar o dano; prestação de serviços à comunidade; liberdade assistida; inserção em regime de semiliberdade; e a internação ${ }^{7}$ em estabelecimento educacional. Estas medidas são definidas

\footnotetext{
${ }^{5}$ São oferecidas 15 vagas e o curso tem duração de 8 meses. Os participantes recebem meio salário mínimo e tem carteira registrada. O acesso à este salário acontece após a saída do menor da UNEI.

${ }^{6}$ O ECA é um conjunto de normas que visa garantir os direitos humanos às crianças e adolescentes. Foi instituído pela Lei 8.069 de 1990 e tem como objetivo, expresso em seu artigo primeiro, proteger a criança e ao adolescente de forma integral.

O Art. 121 traz a internação como medida privativa da liberdade, sujeita aos princípios de brevidade, excepcionalidade e respeito à condição peculiar de pessoa em desenvolvimento: "Art. 122. I - tratar-se de ato infracional cometido mediante grave ameaça ou violência a pessoa; II - por reiteração no cometimento de outras infrações graves; III - por descumprimento reiterado e injustificável da medida anteriormente imposta." (Brasil, 2017, p. 61).
} 
conforme julgamento e condenação em processo legal e variam de acordo com a gravidade e reincidência do ato infracional. No caso de internação, esta deve ser cumprida em unidade específica, como é o caso da UNEI Laranja Doce em Dourados onde aconteceu a oficina de teatro apresentada por este artigo.

\section{Confecção do Projeto}

Após a realização de encontros, leituras, conversas, discussões e pesquisas entre estagiários, orientadora e direção da UNEI, decidimos que iríamos trabalhar com o Teatro do Oprimido de Augusto Boal. No entanto, antes de começarmos efetivamente a construção do projeto foram realizadas entrevistas e conversas preparatórias para saber se os estagiários estavam de fatos prontos para despirse de seus julgamentos, crenças e pré-conceitos, para adentrarem em um espaço de internamento de forma receptiva e aberta para a construção e a troca de experiências teatrais e pessoais entre eles e os participantes da oficina.

Vale ressaltar que apesar de acreditarmos que toda ação teatral contém em si questões políticas e sociais, assim como também a metodologia escolhida Teatro do Oprimido - trabalha com estas questões, na confecção do projeto, o foco foi que o mesmo teria dois propósitos: realizar uma experiência teatral que servisse de aprendizado docente aos estagiários; e proporcionar aos participantes uma formação em teatro. Ou seja, o projeto não teria como objetivo realizar uma ação social que poderia contribuir (ou não) com a reabilitação, ressocialização ou transformação dos internos. Outro ponto importante foi deixar claro que não nos cabia saber ou julgar as infrações cometidas pelos adolescentes.

O Teatro do Oprimido foi criado a partir da década de 1960 por Augusto Boal e trata-se de uma metodologia que reúne exercícios, jogos e técnicas para o fazer teatral visando a conscientização do oprimido através da discussão e reflexão de problemas sociais, políticos e humanos. Inspirado no Teatro Épico de Brecht e na Pedagogia do Oprimido de Paulo Freire, Boal desenvolve um fazer teatral que incentiva a participação efetiva e crítica do público, buscando em todas as suas formas, a transformação da sociedade. A função principal deste teatro seria a de 
dar voz aos oprimidos, trabalhando de forma a ajudar as pessoas a se libertarem, seja de coações, submissões, ou até violências.

O pensamento sensível, que produz arte e cultura, é essencial para a libertação dos oprimidos, amplia e aprofunda sua capacidade de conhecer. Só com cidadãos que, por todos os meios simbólicos (palavras) e sensíveis (som e imagem), se tornam conscientes da realidade em que vivem e das formas possíveis de transformá-la, só assim surgirá, um dia, uma real democracia. (Boal, 2009, p. 16).

De acordo com o autor o senso comum é algo a ser combatido, pois se trata de ações e pensamentos generalizados, que passam a ser naturalizados pelo simples fato de serem reproduzidas constantemente pela sociedade.

Como cidadãos, antes de tudo, como artistas por vocação ou profissão, temos que entender que só através da contracomunicação, da contracultura-de-massas, do contra dogmatismo; só a favor do diálogo, da criatividade e da liberdade de produção e transmissão da arte, do pleno e livre exercício das duas formas humanas de pensar, só assim será possível a liberação consciente e solidária dos oprimidos e a criação de uma sociedade democrática - no seu sentido etimológico, pois, historicamente, a democracia jamais existiu. Dela, pedaços sim. (Boal, 2009, p. 18).

Essa prática teatral para ser realmente libertadora - começando por libertar o espectador de sua passividade e condição de testemunha - só ocorrerá através do combate à cultura de massa, que vem sendo formadora de preconceitos e barreiras para o exercício da liberdade pessoal. A plateia, segundo Boal, deveria ser a protagonista do fenômeno teatral: "O espectador já não delega poderes aos personagens nem para que pensem nem para que atuem em seu lugar. $O$ espectador se libera: pensa e age por si só.” (Boal, 2008, p. 169).

Para a oficina na UNEI, escolhemos trabalhar especificamente com o que Boal denominou de teatro jornal. Criado na década de 1970 esta técnica basicamente consiste em utilizar notícias de jornais para a criação de cenas:

O Teatro Jornal - doze técnicas de transformação de textos jornalísticos em cenas teatrais - consiste na combinação de Imagens e Palavras revelando, naquelas, significados que, nestas, se ocultam. Mostra que um 
jornal, por exemplo, usa técnicas de ficção, tal como a literatura, porém suas: a diagramação, o tamanho das manchetes, a colocação de cada notícia dentro das páginas, etc. (Boal, 2008, p. 18).

Idealizado durante a ditadura militar onde as notícias eram manipuladas de acordo com os interesses do governo, o teatro jornal surge para trazer o outro lado da história, daqueles que eram perseguidos e vítimas da violência.

O Teatro Jornal serve para desmistificar a pretensa imparcialidade dos meios de comunicação. Se jornais, revistas, rádios e TVs vivem economicamente dos seus anunciantes, não permitirão jamais que informações ou notícias verdadeiras revelem a origem e a veracidade daquilo que publicam, ou a quais interesses servem - a mídia será sempre usada para agradar aqueles que a sustentam: será sempre a voz do seu dono. (Boal, 2008, p. 18).

Na atualidade - com a crescente disseminação de Fake News, o movimento para desacreditar a imprensa, propagação de informações (e desinformações) online, distorção de fatos e da ciência - acreditamos ser pertinente trabalhar com esta técnica.

Em geral, para realização do teatro jornal são utilizadas notícias onde há sempre a figura do oprimido e do opressor. O opressor é aquele que pratica a violência, sente como é sê-lo, e dessa forma reconhece as situações em que elas ocorrem. Já o oprimido sente na pele como é ser humilhado. O objetivo é buscar uma solução de forma pacífica (combatendo a opressão), geralmente através de diálogos e de questionamentos, trazendo uma reflexão do opressor sobre suas atitudes, pois o oprimido não pode cair na armadilha de causar uma opressão, mas sim combatê-la.

Para o projeto, selecionamos notícias de crimes que aconteceram em nossa região, mas sem ligação direta com os delitos cometidos pelos menores que iriam participar da oficina. O objetivo foi apresentar situações próximas com as que levaram os adolescentes a detenção, mas sem "apontar dedos", fazendo com que os participantes dialogassem com suas diferentes realidades e suas histórias pessoais ao trazermos uma reflexão sobre a forma como os jornais relatavam estes crimes e as pessoas que os cometiam. 
O principal objetivo era dramatizar as experiências de vida dos participantes e suas percepções do mundo a partir de notícias de jornais, para chegarmos em um resultado prático ${ }^{8}$ a partir do universo ou de temas e questões levantadas pelos próprios participantes.

\section{A Oficina}

A primeira questão prática de se fazer teatro em um espaço de cárcere se inicia com a dúvida em relação ao desconhecido já na entrada à este espaço, que contempla um ritual cheio de incerteza, espera, confinamento e marginalização: entrega e checagem de documentação; revista policial que pode ferir ou desnudar a dignidade; a espera trancados em uma sala - às vezes minutos, às vezes horas - acompanhada da incerteza de não saber se a entrada seria ou não autorizada; a segunda espera na sala reservada à oficina, cheia de dúvidas em saber se teríamos participantes e se estes seriam os mesmos do encontro anterior; o cuidado com que tipo de roupas poderíamos usar ou não durante as oficinas ; quais materiais poderíamos usar; etc., todos estes medos e incertezas fazem parte do que Concílio (2008) chama de "rotina massacrante dos rituais da prisão", que terminava com a chegada dos internos ao local da oficina para aí sim, darmos início ao encontro.

Um dos pioneiros com trabalho de teatro dentro dos presídios brasileiros foi o inglês Paul Heritage, que na década de 1980 começou a desenvolver um trabalho de conscientização da AIDS dentro dos presídios de São Paulo e do Rio de Janeiro. Segundo ele:

O portão da prisão é um espaço de transição marcado por rituais que buscam distanciar o mundo que é deixado para trás do mundo que será adentrado. Visitantes, guardas e prisioneiros, cada um à sua maneira, está sujeito aos ritos dessa passagem, que acontecem tanto na saída quanto

\footnotetext{
${ }^{8}$ O diretor da UNEI solicitou que fosse montado um espetáculo teatral para ser apresentado em um evento e também como finalização do processo. Aceitamos chegar há um produto cênico a ser pensado e construído em conjunto com os participantes e, se fosse da vontade deles, apresentar no evento solicitado e no Núcleo de Artes Cênicas da UFGD.

${ }^{9}$ Foi-nos orientado pelo diretor da instituição a não usar "certos" tipo de roupas, como decotes, roupas curtas ou coladas, assim como brincos, pulseiras e outros acessórios, pois o machismo e a opressão que ocorrem fora da prisão são enfrentados dentro do sistema prisional de forma agravada.
} 
na entrada. (Heritage, 2004, p. 192 ${ }^{10}$ ).

A nós caberia aceitar as regras, caso contrário não seria possível nem entrar no espaço. E assim o fizemos. A oficina foi realizada em uma sala construída especificamente para realização de cursos técnicos para os internos, ou seja, não foi o espaço mais adequado ao fazer teatral, pelo fato do chão ser gelado e sujo e haver carteiras no local. No entanto, os estagiários conseguiram transformar o local em um ambiente acolhedor para dez adolescentes escolhidos pelo diretor da instituição. A cada encontro o número variava devido a questões internas, que iam desde o comportamento dos menores, a punições, rivalidade entre os adolescentes, entre outras causas internas e externas. Alguns participantes que demonstravam bastante interesse na oficina foram impedidos de participar de alguns encontros, aos estagiários não foram dadas informações relevantes apenas o básico de que "estavam sendo punidos por mau comportamento".

Uma das dificuldades na realização da oficina foi a questão do trabalho em grupo. Acreditamos que o teatro é feito em grupo na cumplicidade de ações, corpos e olhares de cada integrante. Diante desta crença foi difícil construir um grupo com um coletivo de pessoas que oscila a cada encontro devido a regras, comportamentos e restrições. Vale ressaltar que estas regras e restrições não foram estabelecidas por este coletivo, mas sim pelo local em que estão, e aos estagiários cabiam apenas aceitar sem questionar.

Se o estabelecimento de um grupo já é difícil em condições "normais", nas condições que se apresentavam dentro de uma Unidade Educacional aliadas a questão do estabelecimento de confiança entre todos os envolvidos, a dificuldade se agrava. Como estabelecer um local de confiança e liberdade (tão necessários ao processo criativo) dentro de um espaço opressor e de confinamento? Concílio e Vetori argumentam que:

O professor que atua no presídio está sempre no difícil papel de mostrar para as alunas que cumprem pena que ele possui um papel diferente do

10 The prison gate is a transitional space marked by rituals that seek to distance the world that is left behind from the world that is entered. Visitors, guards and prisoners each in their way are subject to the rites of this particular passage, which operate on both exit and entrance. (Tradução nossa). 
dos agentes penitenciários, visto que ele não é responsável por vigilância e segurança. Ao mesmo tempo, seu papel pedagógico, não raro, é visto com desconfiança pelos agentes, a quem muitas vezes não é permitido estabelecer uma relação de proximidade com as apenadas - o que poderia ser interpretado como um "afrouxamento" do papel da vigilância. Essa constatação exemplifica uma dentre as várias habilidades que precisamos desenvolver quanto ministramos aula no sistema prisional como estabelecer uma relação que construa a disponibilidade do grupo às propostas teatrais sem parecer que estamos ferindo o "código de conduta" oculto que existe no trato entre o corpo funcional da unidade e as apenadas? É nessa corda-bamba que realizamos nosso trabalho. (Concílio; Vetori, 2019, p. 123).

O teatro dentro de um espaço de privação de liberdade esbarra com limites e regras impostas por terceiros e não acordadas pelo grupo o que gera contradições de ambas as partes. Se por um lado, propor um processo artístico teatral dentro de uma prisão é propor um espaço de liberdade e criatividade inserido em um local destinado ao medo e punições, por outro, aceitar as regras deste ambiente (que vigia e castiga) pode ser considerado não um ato de resistência, mas sim um ato de rendição à um esquema cruel que, na maioria das vezes, não proporciona uma nova chance de inserção à sociedade dos menores infratores, mas sim os estigmatiza e os condena a serem sempre vistos como criminosos.

De nossa parte, escolhemos acreditar que o teatro pode ser uma experiência de liberdade e resistência11 capaz de transformar os indivíduos e instigar o livre pensar crítico, mesmo quando realizado dentro de um espaço onde as regras (de forma explicitas ou não) levam a opressão e à anulação da individualidade.

Durante a oficina, foi possível observar que os encontros foram se transformando em um lugar de escape para os adolescentes. Como eles possuem muito tempo ocioso, em suas rotinas dentro da UNEI, a oficina de teatro acabou por se tornar em um local que além de tirá-los de suas celas ainda oferecia atividades diferentes e divertidas. Em geral, os internos frequentam o ensino regular em um turno, e nos demais, salvo cursos profissionalizantes e a prática de

11 Importante destacar que liberdade além da questão física/geográfica passa por questões de pensamento, criatividade e sentimento. Assim como a ideia de resistir vai além de não ceder a determinado poder, tem relação com a busca de alternativas para transformar ou inventar soluções para este poder. 
esportes (geralmente futebol), eles ficam confinados em seus alojamentos sem atividades ou opções para passar o tempo.

Outro desafio durante a oficina, foi a questão corporal. Os adolescentes começaram o processo animados, mas inibidos: cabeças baixas, braços cruzados ou para trás, voz baixa, atitude defensiva. A cada encontro era preciso ir desconstruindo aos poucos estes corpos, a cada jogo proposto o convite à partilha e à entrega era feito e reiterado e algumas amarras impostas pelo sistema carcerário puderam se romper, outras não.

Os primeiros encontros foram de conversas para que os participantes nos conhecessem e para que nós os conhecêssemos, visando a tentativa de estabelecimento de confiança e a construção de um grupo. Essas conversas serviram para tornar as relações mais naturais e transparentes. Como a rotina deles era muito rígida, tanto em sala de aula quanto na relação com os demais funcionários, foi preciso criar esse código de que eles podiam ser espontâneos e verdadeiros naquele espaço. Os estagiários estavam ali para mediar o encontro com o fazer teatral e jogar junto com eles cada jogo proposto.

As conversas também serviram para estabelecer uma relação de respeito mútuo entre as partes, onde foi estabelecido que cada participante teria o direito de participar ou não da oficina, mas que uma vez ali, respeitariam os colegas e os estagiários; que apesar de não ser um curso técnico, não era uma atividade qualquer e sim um espaço pensado e preparado com objetivos específicos. Trocar a obrigação pela escolha foi uma maneira de apresentar aos adolescentes um ambiente aberto à experimentação e aprendizagem através dos jogos e atividades diferentes de tudo que lhes era oferecido.

Os encontros se iniciavam com aquecimentos a partir de jogos de Viola Spolin e Augusto Boal. Estes jogos trouxeram ao grupo o compartilhamento de vivências através da espontaneidade. Spolin acredita que "a espontaneidade cria uma explosão que por um momento nos liberta de quadros de referência estáticos, da memória sufocada por velhos fatos e informações, de teorias não digeridas e técnicas que são na realidade descobertas de outros" (Spolin, 2010, p. 4). Estes 
jogos também serviram como momentos de descoberta e expressão criativa. Além desse entrosamento necessário ao trabalho em grupo também trabalhamos a criatividade e a espontaneidade.

A cada encontro os participantes ficavam mais à vontade e confiantes, um deles nos relatou que se sentia "leve" durante a oficina. Segundo ele "era como se estivéssemos num parque, ou num lugar livre, apenas brincando e experimentado"12. Aos poucos os estagiários também começaram a ser sentir mais pertencentes aquele espaço e durante a oficina, mesmo estando trancados em uma sala, foi possível criar uma realidade paralela (que não deixava de ser real no momento da oficina) que possibilitou a todos aprender através do sensível e a se reconhecerem enquanto indivíduos pertencentes a um grupo ligados pelo teatro.

Spolin argumenta que "a verdadeira liberdade pessoal e a auto-expressão só podem florescer numa atmosfera onde as atitudes permitam igualdade entre 0 aluno e o professor" (Spolin, 2010, p. 8). Acreditamos que esta liberdade pessoal e auto expressão aconteceram a partir da empatia em relação às diferentes visões e interpretações de realidades de cada participante.

Após o aquecimento eram realizados jogos com o teatro jornal onde os participantes encenavam e recriavam as cenas dos crimes trazidos nas notícias de jornais. A primeira ação foi lermos as notícias em conjunto, este foi um momento rico de troca, onde alguns internos não só se sentiram seguros e à vontade para partilhar com os estagiários as infrações que cometeram, mas também dividiram com o grupo os motivos que os levaram a cometê-las.

Durante a oficina os materiais utilizados foram aqueles disponíveis em sala: carteiras, cadeiras, caixas de papelão, o próprio jornal e tecidos. Primeiro começamos fazendo imagens congeladas, como fotografias onde cada um deveria mostrar uma intenção. Aos poucos, foram sendo inseridos gestos e por último falas. Quando inserimos as falas o jogo perdeu um pouco de intensidade e os corpos perderam tônus. Os adolescentes se sentiram mais à vontade em cena com o uso da fala, mas acabaram por negligenciar as intenções corporais se

12 Relato de um participante da Oficina. 
limitando ao contar. Retomamos as imagens e fomos buscando uma maneira de resgatar o pequeno repertório corporal que já havia sido construído aliando com as falas. O resultado foram improvisações que conseguiram deixar claro ao público o que queriam mostrar e dizer.

Após dois meses de trabalho com improvisações - a partir do teatro jornal conversamos com os participantes sobre começar um processo criativo de construção de cenas que resultassem em um produto cênico. O desafio foi aceito e veio o convite ao grupo para se apresentar no / Seminário Socioeducativo: novas perspectivas para medida de internação em Dourados. Este evento, que teve como objetivo abordar práticas de sucesso em educação e os trabalhos realizados dentro da UNEI Laranja Doce, foi organizado pelo diretor da UNEI e aconteceu fora da unidade.

Em outubro de 2019, cinco adolescentes acompanhados dos estagiários da UFGD apresentaram uma performance para vinte assistentes sociais no auditório do Fórum de Dourados. A performance foi concebida a partir de um documentário feito sobre o projeto Entrado - Projeto de teatro na Prisão de Portugal (2009-2012), o foco foi na criação de metáforas corporais que representassem as situações cotidianas dos internos: adaptação ao internamento; a superlotação; e as lutas dentro da unidade. Toda ação foi realizada sem falas, ao som da música Another Brick in the Wall da banda Pink Floyd.

Este momento foi importante para os adolescentes. Mostrar um trabalho, especialmente fora do ambiente de aula prisional, fez crescer a autoestima dos meninos e os deixou muito empolgados a continuar com a oficina. Mesmo com pouco tempo para ensaio, apresentar a performance para um público, enriqueceu o trabalho teatral, pois o encontro com o público é um momento único e importante de troca e a efetivação do fazer teatral. A performance acabou também por resultar em um ato de ressocialização dos internos, pois naquele momento, mesmo que breve, eles não foram vistos como "criminosos", "delinquentes" ou "marginais", mas sim, artistas, atores que tinham algo a dizer, e desta forma, estes adolescentes se sentiram cidadãos pertencentes à sociedade e não à sua margem. Este ato de enxergar o artista e não o detento é um primeiro 
passo para a construção da cidadania do interno.

Após a apresentação, os adolescentes voltaram à oficina com um novo ânimo e vontade de fazer teatro. Assim, partimos para o processo de criação com vistas de apresentar uma peça em dezembro de 2019 no núcleo de artes cênicas da UFGD. O primeiro ponto a ser decidido foi em relação ao texto, nossa proposta foi de confeccionarmos um texto próprio, no entanto, alguns participantes queriam escolher um texto pronto, foi discutida esta questão e então optou-se pela criação de cenas a partir de improvisações.

Os textos foram escritos a partir de experiências contatas pelos adolescentes, cada participante compartilhou uma história, após este momento de partilha ficou decidido que contaríamos uma história sobre como um adolescente entra para o tráfico de drogas e como é a vida de um menor infrator. Decidimos contar esta história de forma genérica, que tratasse dos desejos e inquietações dos participantes, mas que não tocassem especificamente em casos ou crimes específicos de algum deles. Este distanciamento permitiria que cada um dos adolescentes pudesse pensar em sua própria história fazendo conexões e paralelos com as sua realidade e sua infração, tornando-se ator de sua própria história e refletindo através dela.

Para a construção deste texto, além das histórias contadas, levamos alguns textos, músicas e matérias de jornais sobre a temática escolhida, que serviram de base para improvisações e jogos. A partir destas improvisações os estagiários foram coletando falas e situações que viriam a se consolidar enquanto texto dramático.

Também foram construídos durante a oficina alguns objetos (a partir de materiais recicláveis) que seriam usados nas cenas, como letreiros e pacotes de maconha. No entanto, esta construção passou pela dificuldade de proibição do uso de tesoura ou qualquer outro material cortante.

A maior dificuldade enfrentada durante a oficina foi a questão da saída e rodízio de alguns participantes. Fizemos uma escolha de trabalhar com o mesmo grupo durante todo o processo. Porém, fomos orientados de que o ambiente é 
muito instável e que isso talvez não seria possível, e de fato não foi. O primeiro desfalque ocorreu devido a uma briga entre os internos, onde participantes da oficina estiveram envolvidos (direta ou indiretamente, segundo a direção da UNEI) e por este motivo acabaram sendo punidos: o castigo foi não participar da oficina de teatro.

No encontro logo após a briga fomos avisados (minutos antes) que teríamos adolescentes que nunca haviam participado anteriormente da oficina. O que inviabilizou a continuidade do trabalho programado e os estagiários acabaram por improvisar alguns jogos. Ao final deste encontro, aconteceu uma conversa com a direção da UNEl e nos encontros seguintes, alguns jovens puderam retornar à oficina, mas não todos.

Próximo ao final, com a construção de cenas, alguns dos participantes nos relataram que não se sentiam confortáveis com o processo por não se identificarem com as práticas propostas e optaram por sair da oficina. Também aconteceu de outros dois meninos saírem da oficina para participar de um curso técnico que seria oferecido no mesmo horário. A oficina terminou com apenas três participantes e a frustação de não conseguirmos realizar a apresentação no núcleo de artes cênicas da UFGD, não pela quantidade de participantes, mas por questões burocráticas que inviabilizaram a saída dos internos.

Nossa ideia inicial era levá-los para conhecer a universidade, especialmente o núcleo de artes cênicas, assim como apresentar o resultado da oficina para os acadêmicos de curso de teatro e outros possíveis interessados. No entanto, como esta saída deveria ser viabilizada pelo diretor da unidade uma vez que era preciso autorização do juiz, agentes disponíveis para acompanhar a saída, visita prévia destes agentes ao local para fazer um reconhecimento e um plano de ações em caso de tentativa de fuga e outros riscos. Só fomos informados do cancelamento na semana agendada para a visita e apresentação, o que gerou frustação tanto aos estagiários quanto aos participantes.

Desta forma, a oficina foi encerrada dentro da UNEI com apresentação apenas aos estagiários. A questão que ficou no ar após esta experiência foi: seria 
possível ações teatrais que de fato criassem uma liberdade criadora dentro de um espaço de privação de liberdade? Para responder esta questão resolvemos nos basear no argumento de Luciana Hartmann: "diante da normatização que busca coisificar, repetir, enquadrar conteúdos, educadores e educandos, as experiências de convívio e trocas humanas sempre instauram diferenças, produzem inovações" (2019, p. 29). Para a autora é no encontro real entre professores e alunos que podemos inovar pedagogicamente, e isto de fato ocorreu na UNEI.

Durante a oficina de teatro o encontro entre estagiários e adolescentes aconteceu de forma real e concreta: distintas realidades e percepções de vida que ao trabalharem juntas em um espaço que inclui, encontraram questões que atravessaram ambas as partes e debateram se é ou não possível que o teatro e o fazer artístico provoque ou incite transformações pessoais e sociais. Chegando à conclusão de que o teatro é sim, um caminho possível para a construção da compreensão de questões sociais, e que aquele tempo/espaço - criado durante cada encontro - é um tempo/espaço que transcende os muros do cárcere, contento em si a potência de transformar. Heritage (2004) argumenta que o tempo na prisão é um tempo "que reestrutura arbitrariamente a experiência" dos sujeitos em relação à dinâmica tempo/espaço. Já o teatro opera de modo contrário:

Isso é ainda mais aparente quando o teatro é feito na prisão, um local que reestrutura arbitrariamente a experiência do sujeito no lugar e no tempo. O teatro, ao contrário, desestrutura nossas percepções de tempo e espaço. Em sua própria vivacidade e imediatismo, a performance teatral rompe com medidas de tempo e espaços fazendo tudo acontecer no aqui e agora. Não tem passado e não exige futuro. Ele pede apenas que exista neste momento, enquanto oferece simultaneamente a possibilidade de todo o tempo estar presente em um único instante. (Heritage, 2004, p. 194). ${ }^{13}$

Trabalhar o teatro em um espaço onde quanto mais obediente e submisso o indivíduo for, melhor será para o bom funcionamento da instituição, é trabalhar no

${ }^{13}$ This is all the more apparent when theatre is made in prison, a site that arbitrarily restructures the subject's experience of place and time. Theatre, in contrast, de-structures our perceptions of where and when. In its very aliveness and immediacy, theatrical performance adheres to spatial and temporal boundaries that declare it is only ever here and now. It has no past and demands no future. It asks only that it exists at this moment, while it simultaneously offers the possibility that all time can be present in that one instance. (Tradução nossa). 
limite entre a obediência e subversão às regras. Este espaço, que tem os objetivos de punir e de ressocializar ao mesmo tempo funciona com uma lógica perversa que não leva em conta o sujeito e as causas que o colocaram ali, mas apenas as consequências que eles devem sofrer por estarem ali, ou seja, é capaz de punir, mas não de ressocializar.

Dentro deste espaço foi preciso, antes de mais nada, criar um ambiente propício para a criação que demanda liberdade e trabalho em grupo, mas respeitando a individualidade. Para isso, foi preciso estabelecer uma relação de confiança e cumplicidade entre todos os envolvidos através de jogos, brincadeiras e compartilhamento de histórias e sonhos.

\section{Algumas Reflexões}

De acordo com dados do Departamento Penitenciário Nacional (DEPEN), a população carcerária do Brasil em 2019 era de 773 mil presos, nos colocando como o terceiro país com maior número de pessoas presas no mundo ${ }^{14}$. Ainda segundo o DEPEN, mais de 90\% dos presos são homens - as mulheres são pouco mais de 8\%, (7.265). Dentro desta porcentagem observamos que mais da metade possui entre 18 e 29 anos e 64\% são negros. Como argumenta Heritage:

Os muros que dividem a prisão do resto da sociedade não são os únicos limites que separam os que estão dentro dos que estão fora. Fatores sociais, econômicos e raciais determinam as populações carcerárias globais tanto quanto os órgãos legais e judiciais. (Heritage, 2004, p. 192). ${ }^{15}$

Outro número preocupante diz respeito à superlotação dos presídios: existem 461.026 vagas em todo território nacional, ou seja, faltam mais de trezentas mil vagas para dar conta do número de pessoas em situação carcerária no Brasil, o

\footnotetext{
${ }^{14}$ Estamos atrás apenas dos Estados Unidos da América com 2.2 milhões de presos e da China com 1.6 milhões.

15 The walls that divide the prison from the rest of society are not the only boundaries that separate those within from those without. Social, economic and racial factors determine global prison populations as much as legal and judicial agencies. (Tradução nossa).
} 
que torna quase impossível pensar na ressocialização dos detentos.

Todos estes dados, entre outros, como o fato de que cerca de $41 \%$ dos presos ainda aguardam julgamento, deveriam colocar as questões relacionadas ao sistema penitenciário brasileiro como um dos temas centrais a serem discutidos pelo governo e sociedade, pois ele atravessa questões históricas, sociais, educacionais, de saúde e segurança pública. No entanto, o que estamos acompanhando (nos últimos três anos de forma mais evidente) é um total descaso das autoridades e governos, que propagam entre os cidadãos um discurso de ódio onde "bandido bom é bandido morto", levando a sociedade a não encarar um problema que afeta a vida de tantos brasileiros de forma direta e indireta e não contribui em nada com a busca de soluções para os problemas, mas sim "legitima" ainda mais o preconceito e a ignorância da maioria em relação as causas e consequências de termos os números apresentados acima.

Evidente que existem exceções (pessoas, políticos, entidades, órgãos, etc.) que discutem a questão de forma séria e pertinente, porém não existem na prática, políticas públicas eficientes para mudar a realidade que se apresenta. Vamos tomar como exemplo a questão do espaço físico e da superlotação, trazendo para a UNEl Laranja Doce: localizada no interior do Mato Grosso do Sul. Possui capacidade de atender 40 detentos e estava atendendo 60 (na ocasião da realização da oficina), imagina pensar em grandes centros como São Paulo, Rio de Janeiro, Brasília ou Salvador? No caso da UNEI, existe um aporte de recursos direcionados a melhorias do espaço físico, no entanto, esta verba prioriza a construção de espaços destinado a cursos que priorizem o ensino técnico e não o ensino multidisciplinar, artístico ou o bem estar físico/mental dos menores infratores.

No Brasil, o sistema prisional como acontece na prática tira a identidade individual e generaliza ou estigmatiza o detento, transforma-o em uma figura que incomoda, um número que representa para a sociedade seus piores defeitos e falhas. No entanto, acreditamos que a partir de um novo olhar que preze a individualização do infrator - o tratando como um sujeito que cometeu erros, mas que é um sujeito de direitos - esta realidade pode ser modificada. Especialmente 
quando falamos de menores infratores e medidas socioeducativas, acreditamos que a partir de práticas culturais, artísticas, sociais, educacionais e de profissionalização será possível cumprir o que preceitua o ECA.

Se analisarmos os documentos oficiais, em relação às "punições" por "infração penal", podemos observar que no discurso dominante se objetiva a recuperação do infrator, ou seja, as medidas punitivas visam fazer com que o adolescente consiga ser integrado ao convívio social e familiar com perspectiva de futuro e não de reincidência. No entanto, a prática diária nos centros e unidades de atendimento socioeducativos, assim como as perspectivas de futuro dos menores infratores são divergentes do discurso enunciado pelas leis, pois este tênue equilíbrio entre o "punir" e o "reabilitar" entra em contradição com os procedimentos pedagógicos e disciplinares destas instituições, assim como com a realidade social e histórica que os aguardam após o cumprimento de sua pena.

Para que o discurso seja efetivado, é preciso políticas públicas que enfatizem - além da ressocialização do adolescente através da educação e com perspectivas profissionais (que são importantes) - o cuidado com a sua formação em termos psíquicos e familiares; a atenção aos seus desejos e sonhos, compreendendo cada indivíduo como particular; a garantia de seus direitos básicos durante e após o cumprimento de suas medidas socioeducativas; entre outras políticas. Estas ações podem ser a diferença entre o menor infrator, após cumprir seu período de reclusão, carregar consigo os aprendizados que vivenciou ou as consequências deste período.

Por este prisma e pela experiência vivenciada acreditamos que o teatro pode ser uma política pública de desenvolvimento social que age em conjunto com políticas de segurança pública capazes de provocar reflexão, transformação e ação, pois as atividades artísticas de forma geral têm o potencial de trabalhar com menores infratores questões importantes capazes de gerar a conscientização pessoal e coletiva e ajudar na prevenção de reincidência delitiva.

Trabalhar com o teatro dentro de penitenciárias e centros para menores infratores, através do retrato de suas próprias histórias de vidas e das histórias 
que os cercam é uma forma de pensar qual era e qual será a relação do detento com a sociedade através da experiência criativa. Experiência esta, com potencial de ser libertária, contribuindo para a expressão e construção dos indivíduos. Segundo Boal:

Teatro é a capacidade dos seres humanos (ausente nos animais) de se observarem a si mesmo em ação. Os humanos são capazes de se ver no ato de ver, capazes de pensar suas emoções e de se emocionar com seus pensamentos. Podem se ver aqui e se imaginar adiante, podem se ver como são agora e se imaginar como serão amanhã. (Boal, 2009, p. 15).

Observar a si próprio em uma ação e poder refletir sobre a ação que foi realizada através do teatro é uma maneira de levantar discussões sobre os mais distintos temas. Esta ação faz com que os detentos possam se sentir livres dentro de um espaço que aprisiona, não só seus corpos, mas também suas histórias de vida, suas realidades sociais e culturais. Desta maneira, o teatro pode ser um agente transformador capaz de enriquecer as capacidades sociais individuais e grupais.

Evidente que não podemos falar de um teatro para prisão, como uma fórmula que se aplica a qualquer situação de cárcere. Cada instituição tem necessidades, rotinas e regras particulares e específicas. Cada proposta deve ser realizada levando em conta os indivíduos que farão parte do processo. Cada experiência será única e impossível de ser reproduzida. Mas todos elas podem ser facilitadoras da integração em grupo e social: "No mínimo, o teatro oferece a possibilidade de que os prisioneiros, que são objetos da vigilância do sistema e das denúncias da sociedade, possam começar a olhar e falar como sujeitos em suas próprias vidas" (Heritage, 2004, p.195) ${ }^{16}$. Como todo o processo criativo, o teatro pode vir a se tornar uma experiência de liberdade na vida de um interno. Este gosto de liberdade é capaz de ajudar na ressocialização do sujeito através do reconhecimento de sua identidade.

Realizar a prática de estágio dentro da UNEI nos levou a refletir sobre qual é a função do artista docente ou quais são suas possibilidades de ação dentro de 
um espaço físico que aprisiona, condena, vigia e puni. Mesmo que durante a construção do projeto esta não tenha sido a questão principal, não tem como vivenciar uma experiência sem sermos transformados por ela. Presenciar o nervosismo dos meninos com a apresentação; o medo de passarem vergonha; o empenho em decorar uma marcação cênica e depois um texto; a ansiedade e a vontade de se apresentarem; o empenho na confecção de objetos para cena; etc.; foi bastante rico, prazeroso e humanizador.

Se colocar no lugar do outro é um dos preceitos do fazer teatral, assim como um dos requisitos para conhecermos a nós mesmos. Como argumenta Foucault é através do outro que eu sei quem eu sou, porque o outro funciona como um espelho. Ao interpretar um personagem somos capazes de nos colocar no lugar dele, ter empatia e entender suas motivações. Talvez este seja um exercício que precisamos fazer em nosso cotidiano, praticar empatia e lutar pela equidade. A maneira como nos comportamos enquanto sociedade, julgando e punindo de diferentes formas, só faz aumentar os problemas sociais do nosso país. Ao tentar combatermos a violência com mais violência, acabamos por nos tornar parte do problema e não da solução.

Para concluir, gostaríamos de deixar a reflexão do escritor francês Maurice Druon a partir de sua obra O Menino do Dedo Verde. Nela o pequeno Tistu está aprendendo que a cadeia é o lugar onde as pessoas são castigadas e punidas, e para isso elas ficam trancadas em um espaço cheio de grades altas e com uma "imensa parede cinzenta, sem uma única janela" (Druon, 2013, p. 39). Tudo isso para impedi-las de fugir e para ensiná-las a não serem pessoas "más". Imediatamente Tistu conclui que "se esta cadeia não fosse tão feia, talvez eles tivessem menos vontade de fugir" (p. 40) e os prisioneiros aprenderiam mais depressa como serem bons. Como Tistu era um menino que possuía um dom (tinha o dedo verde), logo arquiteta de ir até a prisão na calada da noite e colocar seu dedo em ação. No dia seguinte a cadeia amanhece repleta das mais diversas espécies de flores e plantas o que causa grande alvoroço na população e deslumbramento dos prisioneiros que:

Como já não viam grades em suas celas, nem arame farpado ou pontas 
de ferro sobre os muros, esqueceram-se de fugir. Os mais resmungões pararam de reclamar, tão entusiasmados estavam em contemplar o que os cercava; os maus perderam o costume de zangar-se e brigar. A madressilva que brotava nas fechaduras impedia às portas que fechassem, mas os próprios ex-prisioneiros recusaram-se a ir embora, tal o gosto que tomaram pela jardinagem. E a cadeia de Mirapólvora foi apontada como modelo em todo o mundo." (Druon, 2013, p. 49).

Esta história ilustra de forma lúdica a ideia de que este espaço destinado a punir e ressocializar deve ser repensado pela sociedade, pois a forma como se apresenta nos dias de hoje ele acaba apenas por punir, e por vezes produzir mais criminosos e violência. Em relação à pergunta do começo desta reflexão: como realizar uma prática alicerçada na liberdade de expressão, corporal e do pensamento, dentro de um espaço que institui regras rígidas, punições, repressão, coerção, entre outras práticas de aprisionamento físico, intelectual e psicológico? Chegamos à conclusão de que, apesar da prática ser difícil, a resposta é simples: fazendo Arte.

\section{Referências}

BALFOUR, Michel. Theatre in Prison: Theory and Practice. Bristol, Intellect Books, 2004.

BOAL, Augusto. A Estética do Oprimido. Rio de Janeiro: Garamond, 2009.

BOAL, Augusto. Teatro do oprimido e outras poéticas políticas. Rio de Janeiro: Civilização Brasileira, 2008.

CONCILIO, Vicente. Teatro e prisão: dilemas da liberdade artística. São Paulo: Hucitec, 2008.

CONCILIO, Vicente. VETORI, Caroline. Relato solto de uma oficina atrás das grades: Um Processo de Escrita Teatral no Presídio Feminino de Florianópolis. laçá: Artes da Cena, Macapá, v. 2, n.2, p. 120-132, 2019.

DRUON, Maurice. O menino do dedo verde. Rio de Janeiro: José Olympio editora, 2013. Tradução de D. Marcos Barbosa. 97 edição.

FOUCAULT, Michel. Vigiar e Punir - história da violência nas prisões. Vozes, Petrópolis, 1997. 
HARTMANN, Luciana e SILVA, Sonaly Torres. Pequenas Resistências: contação de histórias, performance e protagonismo infantil na escola. Urdimento, Florianópolis, v. 1 n.34, p. 19-35, 2019.

HERITAGE, Paul. Real Social Ties? The Ins and Outs of Making Theatre in Brazilian prisons. In: BALFOUR, Michel. Theatre in Prison: Theory and Practice. Bristol, Intellect Books, 2004, p. 184-201.

ROCHA, Maria de Lourdes Naylor. Teatro na Prisão: A Dramaturgia da Prisão em Cena. Tese (Doutorado em Teatro) - Programa de Pós-Graduação em Teatro, Universidade Federal do Estado do Rio de Janeiro, 2006.

SPOLIN, Viola. Improvisação para o Teatro. Trad. e Rev. Ingrid Dormien Koudela e Eduardo José de Almeida Amos. São Paulo: Perspectiva, 2010.

\section{Sites}

http://depen.gov.br/DEPEN/depen/sisdepen/infopen/infopen. Acesso em: 29 abril 2020

Estatuto da Criança e do Adolescente - Lei n 8.069 de 13 de julho de 1990, disponivel

em https://www2.senado.leg.br/bdsf/bitstream/handle/id/534718/eca 1ed.pdf

Recebido em: 22/07/2020

Aprovado em: 28/09/2020 